\title{
Limited Recovery of Pineal Function after Regeneration of Preganglionic Sympathetic Axons: Evidence for Loss of Ganglionic Synaptic Specificity
}

\author{
Jaisri R. Lingappa ${ }^{1}$ and Richard E. Zigmond ${ }^{1,2}$ \\ ${ }^{1}$ Department of Biological Chemistry and Molecular Pharmacology, Harvard Medical School, Boston, Massachusetts 02115, and ${ }^{2}$ Department of \\ Neurosciences, Case Western Reserve University, Cleveland, Ohio 44106
}

\begin{abstract}
The cervical sympathetic trunks (CSTs) contain axons of preganglionic neurons that innervate the superior cervical ganglia (SCGs). Because regeneration of CST fibers can be extensive and can reestablish certain specific patterns of SCG connections, restoration of end organ function would be expected. This expectation was examined with respect to the pineal gland, an organ innervated by the two SCGs. The activity of pineal serotonin $N$-acetyltransferase (NAT) exhibits a large circadian rhythm that is dependent on the sympathetic input of the gland, with high activity at night. Thirty-six hours after the CSTs were crushed bilaterally, nocturnal NAT was decreased by $99 \%$. Three months later, enzyme activity had recovered only to $15 \%$ of control values, a recovery dependent on regeneration of CST fibers. Nevertheless, a small day/night rhythm was present in lesioned animals. Neither the density of the adrenergic innervation of the gland nor the ability of an adrenergic agonist to stimulate NAT activity was reduced in rats with regenerated CSTs. In addition, stimulation of the regenerated CST at a variety of frequencies was at least as effective in increasing NAT activity as seen with control nerves. These data suggest that the failure of pineal function to recover is not attributable to a quantitative deficit in the extent of reinnervation or synaptic efficacy. Rather, we suggest that there is some loss of specificity in the synaptic connections made in the SCG during reinnervation, resulting in a loss of the central neuronal information necessary for directing a normal NAT rhythm and thus normal pineal function.
\end{abstract}

\section{Introduction}

In the peripheral nervous system, lesioned nerve fibers are capable of regenerating and reinnervating denervated targets. One system in which this capacity has been studied extensively is the preganglionic cervical sympathetic trunk (CST). This fiber bundle contains the axons of preganglionic sympathetic neurons whose cell bodies are located primarily in the intermediolateral nucleus (IML) of the upper thoracic spinal cord and whose terminals are located in the superior cervical ganglia (SCG) (Gabella, 1976; Rando et al., 1981). After the CST is lesioned, whether by cutting, crushing, or freezing, many of the preganglionic fibers regenerate and reinnervate neurons in the SCG (Hopkins and Lambert, 1972; Bray and Aguayo, 1974; Raisman et al., 1974). Experiments in the cat by Langley $(1895,1897)$ and subsequently in the guinea pig by Nja and Purves $(1977,1978)$ demonstrated that certain aspects of the original specificity of

Received Aug. 8, 2012; revised Dec. 18, 2012; accepted Jan. 29, 2013.

Author contributions: J.R.L. and R.E.Z. designed research; J.R.L. performed research; J.R.L. analyzed data; J.R.L. and R.E.Z. wrote the paper.

This work was supported by National Institutes of Health Grant NS 17512, Predoctoral Training Grants GM 07226 and GM 07306 (J.R.L.), and Research Scientist Development Award MH 00162 (R.E.Z.). We thank Claire Baldwin, Chauncey Bowers, and Jan Henderson for advice and technical help during this study and Maryanne Pendergast and Jon Niemi for help with the figures.

Correspondence should be addressed to Richard E. Zigmond, Department of Neurosciences, Case Western Reserve University, 10900 Euclid Avenue, Cleveland, 0H 44106-4975. E-mail: rez@case.edu.

J. R. Lingappa's present address: Department of Global Health, University of Washington, 1616 Eastlake Avenue East, Suite 305, Seattle, WA 98102. E-mail: jais@u.washington.edu.

DOI:10.1523/JNEUROSCI.3829-12.2013

Copyright $\odot 2013$ the authors $\quad 0270-6474 / 13 / 334867-08 \$ 15.00 / 0$ neuronal connections are reestablished as a result of this regeneration. For example, stimulation of the first thoracic ventral root (T1), both in control cats and after regeneration following transection of the CST, leads to dilation of the pupil and widening of the palpebral fissure with very little piloerection on the face and little vasoconstriction in the ear. Stimulation of T4 has the opposite effects in both control and previously lesioned animals (Langley, 1895, 1897).

Surprisingly, little attention has been directed at determining whether or not normal autonomic function is restored as a consequence of regeneration of the CST. We have examined this question using the sympathetic innervation of the rat pineal gland as a model system. An advantage of this system is that it is possible to quantify an innervation-dependent feature of pineal function, namely, the circadian rhythm in the activity of the enzyme that catalyzes the synthesis of $\mathrm{N}$-acetylserotonin, the precursor of the pineal hormone melatonin (for review, see Borjigin et al., 2012). Klein and Weller (1970) showed that the activity of this enzyme, serotonin $N$-acetyltransferase (NAT), increases dramatically in the pineal gland during the nighttime. A number of studies have established that the rhythm in NAT activity is dependent on the sympathetic innervation of the gland. Retrograde trans-synaptic labeling from the rat pineal gland identified most of the second-order neurons in the pineal circuit to be in the IML at levels T1-T3 (Larsen et al., 1998). The nighttime increase in pineal NAT activity can be blocked by cutting the two CSTs (Klein et al., 1971) or the two postganglionic internal carotid nerves (Zigmond et al., 1981; Bowers et al., 1984a). The latter 


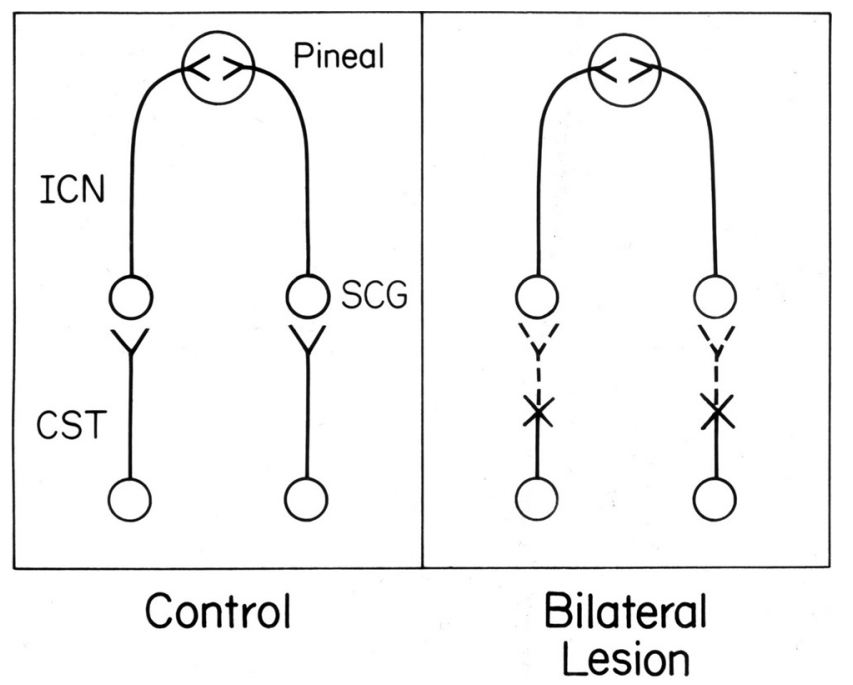

Figure 1. A schematic diagram of the sympathetic innervation of the rat pineal gland and the location of the sites where lesions were made. The pineal gland is innervated by neurons whose cell bodies are in the SCG and whose fibers exit from this ganglion via the internal carotid nerves (ICN). These neurons are themselves innervated by preganglionic neurons whose cell bodies are in the thoracic spinal cord and whose axons reach the SCG via the CSTs. The CSTs were lesioned bilaterally by crushing both nerve trunks with watchmaker forceps $6-8 \mathrm{~mm}$ proximal to the SCG.

contain axons of the SCG neurons that innervate the pineal gland (Bowers et al., 1984b; see Fig. 1). There is a second postganglionic trunk of the SCG, the external carotid nerve, but it neither innervates the pineal gland nor is involved in the regulation of NAT activity (Zigmond et al., 1981, 1985; Bowers et al., 1984b). The nighttime increase in NAT activity can be mimicked by electrical stimulation of either of the two CSTs (Volkman and Heller, 1971; Bowers and Zigmond, 1980, 1982) or the two internal carotid nerves (Bowers and Zigmond, 1982). In the present study, we examined whether the circadian rhythm in pineal NAT activity is restored to normal after regeneration of the rat CST.

\section{Materials and Methods}

Animals and surgery. Male Sprague Dawley rats (100-125 g; 35 d old) were housed under controlled lighting conditions ( $12 \mathrm{~h}$ light/dark cycle) and were given food and water ad libitum for at least $10 \mathrm{~d}$ after their arrival from the supplier (Charles River Breeding Laboratories). All surgeries were performed during the daytime. Animals were anesthetized with chloral hydrate $(735 \mathrm{mg} / \mathrm{kg}$, s.c.; Sigma), and both CSTs were exposed and crushed with fine watchmaker forceps $4-6 \mathrm{~mm}$ proximal to the SCG (Fig. 1). Sham-operated animals had their CSTs exposed but not crushed. In one group of animals, the CSTs were lesioned twice, the second time by cutting out a short section of the trunk 1 week before the pineal glands were removed.

Biochemical assays for NAT and tyrosine hydroxylase activity. NAT activity was measured $7-8 \mathrm{~h}$ into the dark period, by which time enzyme activity in unoperated animals in our laboratory has been shown to reach maximal nighttime levels (Bowers and Zigmond, 1980). Rats were removed from the animal room individually, in a light-tight box, and decapitated in a dark room using dim red light (Kodak Safelight filter 2, $15 \mathrm{~W}$ bulb). Pineal glands were removed quickly, frozen on dry ice, and stored at $-80^{\circ} \mathrm{C}$ until assayed. In one experiment, pineal glands were removed at four different times spaced throughout a single light/dark cycle. NAT activity was determined by the method of Deguchi and Axelrod (1972), as modified by Parfitt et al. (1975). Details of the assay conditions have been reported previously (Bowers and Zigmond, 1982). The protein content of pineal glands was measured using the method of Lowry et al. (1951) with bovine serum albumin as the standard.
As a biochemical index of possible long-term effects of cutting the CSTs on the principal neurons in the ganglia, tyrosine hydroxylase (TH) activity was measured in homogenates of SCG in the presence of brocresine, an inhibitor of L-3,4-dihydroxyphenylalanine (DOPA) decarboxylase. The reaction conditions were as described by Ip and Zigmond (1985), except that non-radioactive tyrosine was used and the reaction was stopped by adding $1 \mathrm{ml}$ of $0.5 \mathrm{~m}$ Tris buffer, $\mathrm{pH} 8.6$, containing 0.1 mM EDTA and $25 \mathrm{~nm}$ epinephrine, the latter as an internal standard. The catecholamines were then adsorbed onto acid-washed alumina and eluted with $150 \mathrm{~mm}$ phosphoric acid containing $0.1 \mathrm{~mm}$ EDTA. An aliquot was assayed for DOPA content, using HPLC and electrochemical detection as described by Erny et al. (1981) with minor modifications.

Measurement of NAT responses to pharmacological and physiological stimulation. To determine the sensitivity of the pineal gland to catecholamines, animals were injected subcutaneously $5-6 \mathrm{~h}$ into the daytime with l-isoproterenol $\mathrm{HCl}$ (Sigma or Pfalz and Bauers) dissolved in $0.9 \% \mathrm{NaCl}$. Control animals were injected with the vehicle alone. Three hours after the injections, by which time the isoproterenol stimulation of NAT activity is maximal (Brownstein et al., 1973), the animals were decapitated, and their pineal glands were removed and frozen.

To determine the response of the pineal gland to sympathetic nerve stimulation, animals were anesthetized as described above, $4-8 \mathrm{~h}$ into the daytime. Both CSTs were exposed and cut $6-8 \mathrm{~mm}$ caudal to the SCG. (In the case of previously lesioned animals, the CSTs were always cut proximal to the site of the original lesion.) During the stimulation, the animal's body temperature was maintained at $37^{\circ} \mathrm{C}$ using a heat lamp. The CSTs were stimulated bilaterally using suction electrodes, as described by Bowers and Zigmond (1982). The current used for stimulation was twice that required to produce maximal exopthalmos at a stimulation frequency of $10 \mathrm{~Hz}$ and pulse duration of $0.5 \mathrm{~ms}$. The currents used ranged from 200 to $800 \mu \mathrm{A}$. The duration of nerve stimulation was $3 \mathrm{~h}$. The animal's level of anesthesia during the stimulation was monitored using a light foot pinch, and booster injections of chloral hydrate were given as needed. Control animals (no stimulation) were anesthetized, their CSTs were exposed and cut, and the animals were maintained under anesthesia for $3 \mathrm{~h}$. At the end of the stimulation or sham-stimulation periods, animals were quickly decapitated, and their pineal glands were removed and frozen.

Measurement of the sympathetic innervation of the pineal gland. To examine the adrenergic innervation of the pineal gland in sham-operated and previously lesioned animals, rats were decapitated 6-9 h into the dark period, and their pineal glands removed. Some animals were injected intraperitoneally with D,L- $\alpha$-methylnorepinephrine ( $1 \mathrm{mg} / \mathrm{kg}$; Regis Chemical) $1 \mathrm{~h}$ before removal of their pineal glands. Catecholaminergic nerve processes were examined in $10 \mu \mathrm{m}$ tissue sections using a modified glyoxylic acid method (Dela Torre and Surgeon, 1976; De la Torre, 1980). To measure the density of fluorescent processes, a strip through the midline of every 10th section of the pineal gland was photographed and analyzed using a grid overlay (for details, see Lingappa and Zigmond, 1987a). In addition, montages were made of representative sections from each group.

Statistics. Data were analyzed using the Student's $t$ test for two means (two-tailed, except when noted).

\section{Results}

Peak night NAT activity was examined 1.5 and $80 \mathrm{~d}$ after the CSTs were crushed bilaterally. At the early time point, NAT activity in lesioned animals was only $1 \%$ of that found in sham-operated control animals (Fig. 2), confirming the finding of Klein et al. (1971) that the rhythm in NAT activity is almost entirely dependent on sympathetic input. At 80 d, by which time the CSTs would be expected to have regenerated extensively (Raisman et al., 1974), peak night NAT activity was only $15 \%$ of the activity seen in sham-operated animals (Fig. 2). In seven different experiments, the recovery of peak night NAT activity 2.5-4 months after CST lesions was consistently low, ranging from 7 to $18 \%$ of control values, with a mean recovery of $13 \%$.

The time course of the recovery of nocturnal NAT activity was assessed by measuring enzyme activity 30,60 , and $100 \mathrm{~d}$ after 


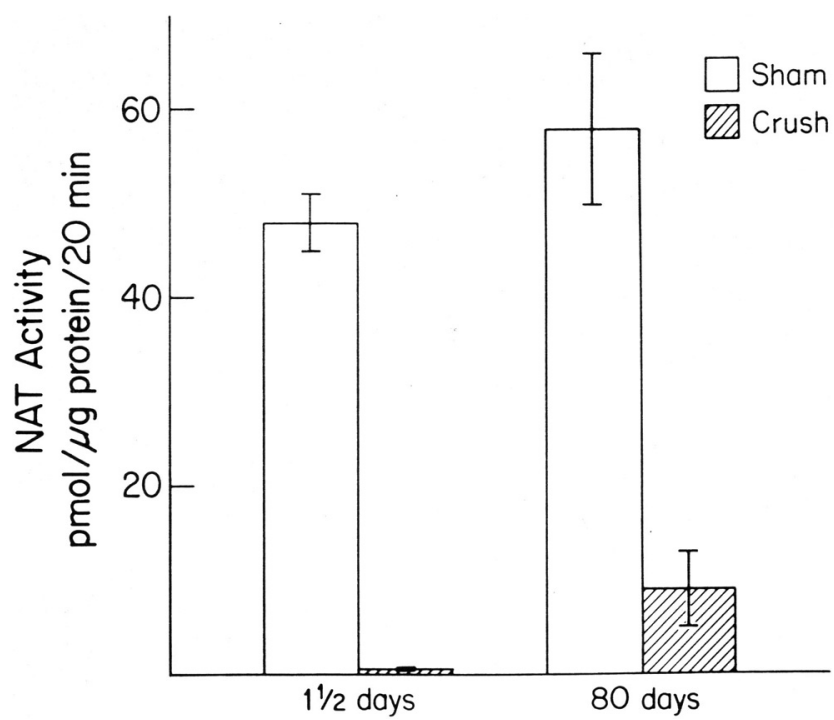

Figure 2. Recovery of peak night NAT activity after crushing of the CST bilaterally. On the second night (1.5 d) after crushing both CSTs (Crush) or after a sham operation (Sham), pineal NAT activity was measured $7-8 \mathrm{~h}$ into the dark period. In a separate experiment, nocturnal NAT activity was measured $80 \mathrm{~d}$ after these operations. The data presented are the mean \pm SEM vales of six to eight pineal glands. Although the NAT activities in the pineal glands of the two sham-operated groups were not significantly different, the enzyme activity in pineal glands of animals $80 \mathrm{~d}$ after crushing both CSTs was significantly higher than that in animals $1.5 \mathrm{~d}$ after the lesion $(p<0.05)$.

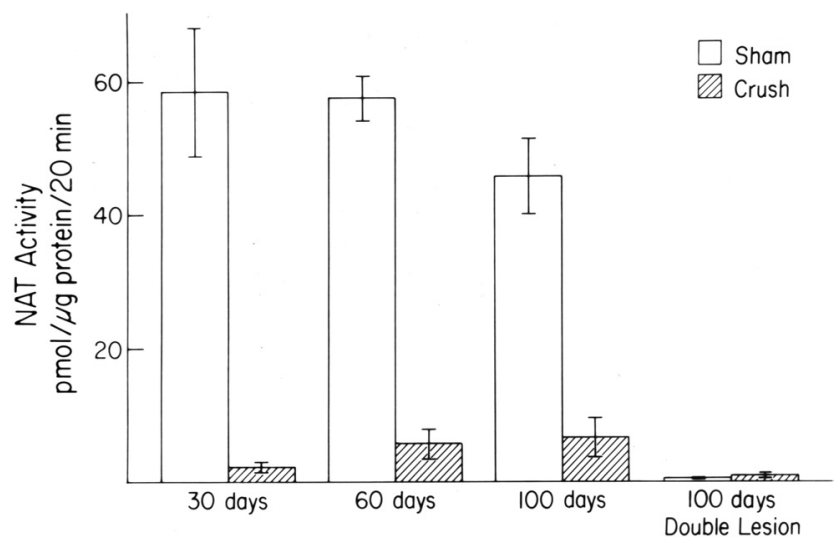

Figure 3. Recovery of peak night NAT activity at different times after bilateral crushing of the CST and the effect of a double lesion on this recovered activity. Pineal NAT activity was measured 7-8 $\mathrm{h}$ into the dark period, 30,60, and $100 \mathrm{~d}$ after bilateral crushing of the CST (Crush), or after a sham operation (Sham). Each bar represents the average of five to six pineal glands. One week before the removal of pineal glands at $100 \mathrm{~d}$, both CSTs were cut in one group of previously sham-operated and in one group of previously lesioned animals (Double Lesion). NAT activity was extremely low in these latter two groups, and the two groups were not significantly different from each other.

crushing the CST. The results suggest that the recovery of nocturnal NAT activity reaches a plateau by $60 \mathrm{~d}$ after the lesion (Fig. 3). Ninety-three days after the initial operation, both CSTs were cut in one group of sham-operated rats and in one group of previously lesioned rats. When NAT activity was measured 1 week later, it had decreased to extremely low values in both of these groups (Fig. 3).

The NAT measurements described above were made 7-8 h into the dark period, at which time enzyme activity in unoperated animals has been found to reach peak levels (Bowers and Zigmond, 1980). It is possible that, in rats with regenerated CSTs,

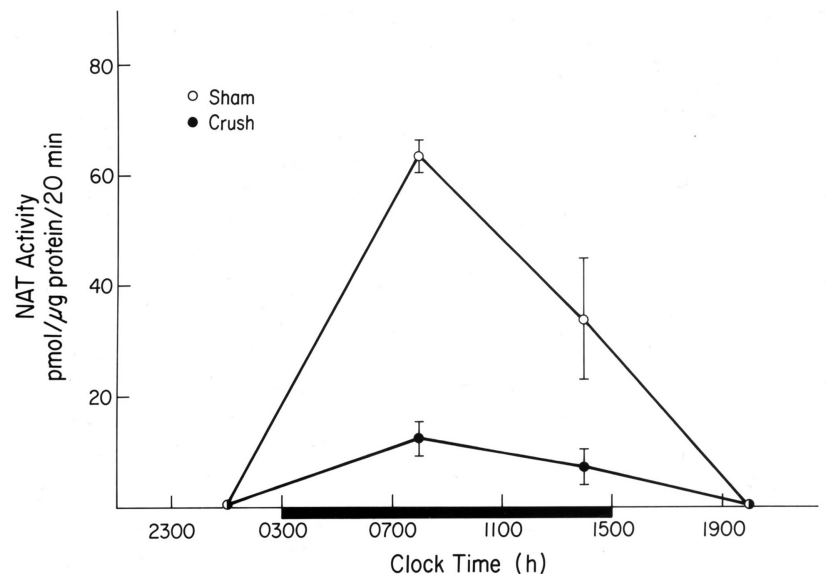

Figure 4. Day/night rhythm in NAT activity 2 months after bilateral crushing of the CST. Two months after bilateral crushing of the CST (Crush) or a sham-operation (Sham), NAT activity was measured 5 and $11 \mathrm{~h}$ into the dark period and 5 and $10 \mathrm{~h}$ into the light period. The horizontal dark line indicates the time during which the lights were off in the animal room. Each point represents the average of five to six pineal glands. NAT activity in the previously lesioned animals was significantly lower than that in the control animals at both $5 \mathrm{~h}(p<0.025)$ and $11 \mathrm{~h}$ ( $p<0.05$, by a one-tailed test) into the dark period.

Table 1. Ganglionic TH activity $80 \mathrm{~d}$ after bilateral crushing of the CST

\begin{tabular}{lll}
\hline & TH activity (nmol DOPA/ganglion/h) & Protein content ( $\mu$ g protein/ganglion) \\
\hline Sham & $11.3 \pm 0.7$ & $291 \pm 20$ \\
Crush & $10.8 \pm 1.5$ & $245 \pm 35$
\end{tabular}

TH activity and protein content were measured in homogenates of SCG 80 d after bilateral crushing of the CST (Crush) or sham operations (Sham). TH activity was assayed at $\mathrm{pH} \mathrm{6.0,} \mathrm{using} \mathrm{a} \mathrm{saturating} \mathrm{concentration} \mathrm{of}$ 6-methyltetrahydropterin ( $3.2 \mathrm{mM}$ ). Average values for the right and left ganglia of each animal were obtained. The data represent the mean \pm SEM values for groups of four animals.

pineal NAT activity reaches normal nocturnal levels, but that it does so at a different time of night than that seen in shamoperated animals. Alternatively, it is possible that NAT activity in animals with regenerated CST does not exhibit any diurnal rhythmicity. To examine both of these possibilities, NAT activity was measured 5 and $11 \mathrm{~h}$ into the dark cycle and 5 and $10 \mathrm{~h}$ into the light cycle, 2 months after sham operations or bilateral crushing of the CST. In both the lesioned and control groups, NAT activity was significantly higher at night than during the day (Fig. 4). Nocturnal NAT levels in rats with regenerated CSTs were $\sim 20 \%$ of those of sham-operated rats at both time points examined. There were no significant differences between the day values of the sham-operated and lesioned groups.

One possible cause for the decrease in the amplitude of the rhythm in NAT activity could be orthograde trans-synaptic degeneration of some of the postganglionic neurons that innervate the pineal gland. Two indices were used to assess the integrity of the postganglionic neurons 2 months after a preganglionic nerve lesion. The first index was the activity of ganglionic $\mathrm{TH}$, the enzyme that catalyzes the rate-limiting step in norepinephrine biosynthesis. When the activity of this enzyme was measured in the SCG, no significant difference was found between ganglia from previously lesioned or sham-operated animals (Table 1).

As a second index of the integrity of the postganglionic neurons, the adrenergic innervation of the pineal gland was examined using catecholamine fluorescence histochemistry. Unexpectedly, the density of fluorescent processes in the pineal glands of previously lesioned animals was only $30 \%$ of that found in sham-operated animals (Fig. 5, Table 2). To determine whether the adrenergic processes in the pineal glands of the lesioned animals were actually miss- 
ing or whether their norepinephrine content was too low to be detected, animals were injected with the false neurotransmitter $\alpha$-methylnorepinephrine $1 \mathrm{~h}$ before their pineal glands were removed. Although $\alpha$-methylnorepinephrine had no effect on the density of fluorescent processes in the pineal glands of sham-operated animals, it dramatically increased the density of these processes in previously lesioned animals (Fig. 5, Table 2). Furthermore, after $\alpha$-methylnorepinephrine administration, the densities of fluorescent processes in the pineal glands of sham-operated and previously lesioned animals were no longer significantly different.

To determine whether the failure of recovery of nighttime NAT activity after regeneration of the CST could be explained by a decreased responsiveness of the pineal gland to $\beta$-adrenergic agonists, animals were injected with isoproterenol, a $\beta$-adrenergic agonist that is not taken up by sympathetic nerve terminals (Iversen, 1975), and is, therefore, useful for examining postsynaptic adrenergic responsiveness. The maximal efficacy of isoproterenol in increasing pineal NAT activity was twice as high 3 months after bilateral crushing of the CST as it was 3 months after a sham operation (Fig. 6). In addition, isoproterenol was more potent in rats with regenerated CSTs. At a dose of $0.2 \mathrm{mg} / \mathrm{kg}$, there was no significant increase in NAT activity in sham-operated animals, but this dose of isoproterenol increased NAT activity in rats with regenerated CSTs to approximately half of its maximum value $(p<0.005)$.

Given that the pineal glands of rats with regenerated CSTs can respond to $\beta$-adrenergic agonists, it is possible that their low nocturnal NAT activity is attributable to a failure of synaptic transmission, at the level of either the SCG or the pineal gland. To examine whether there was a failure of transmission in this system, we electrically stimulated the regenerated CSTs and examined the effects of this stimulation on NAT activity. First, the effects of various frequencies of stimulation on NAT activity were determined in control animals. Unoperated animals were anesthetized, and both CSTs were stimulated during the daytime (Fig. 7A). Stimulation at $10 \mathrm{~Hz}$ for $3 \mathrm{~h}$ raised NAT activity to peak night values, whereas stimulation at 5 or $2.5 \mathrm{~Hz}$ produced submaximal increases. Stimulation of the CSTs at $1 \mathrm{~Hz}$ did not increase NAT activity above control values.

The effects of preganglionic nerve stimulation on NAT activity were then examined in sham-operated rats and previously lesioned animals. Three months after the operations, both CSTs were stimulated for $3 \mathrm{~h}$ during the daytime (Fig. $7 B$ ). The responses of pineal glands from sham-operated animals were similar to those seen in the preceding experiment in unoperated animals (Fig. 7, compare $A, B$ ). Surprisingly, at all frequencies of stimulation, the responses of pineal glands from animals with

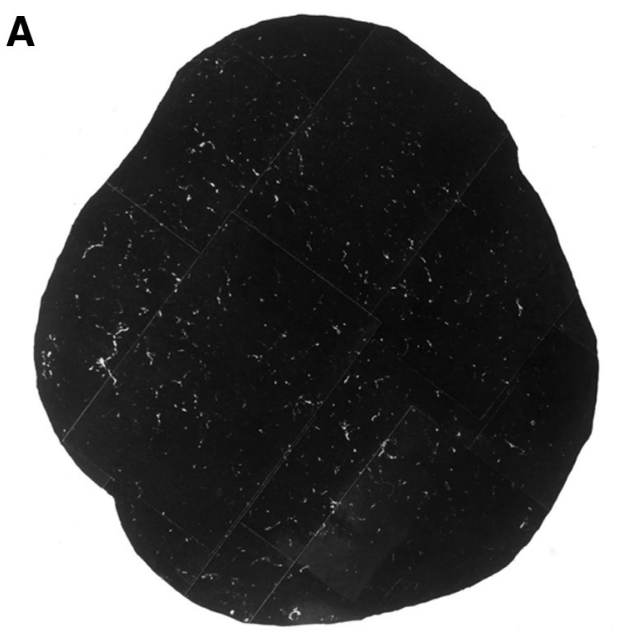

B
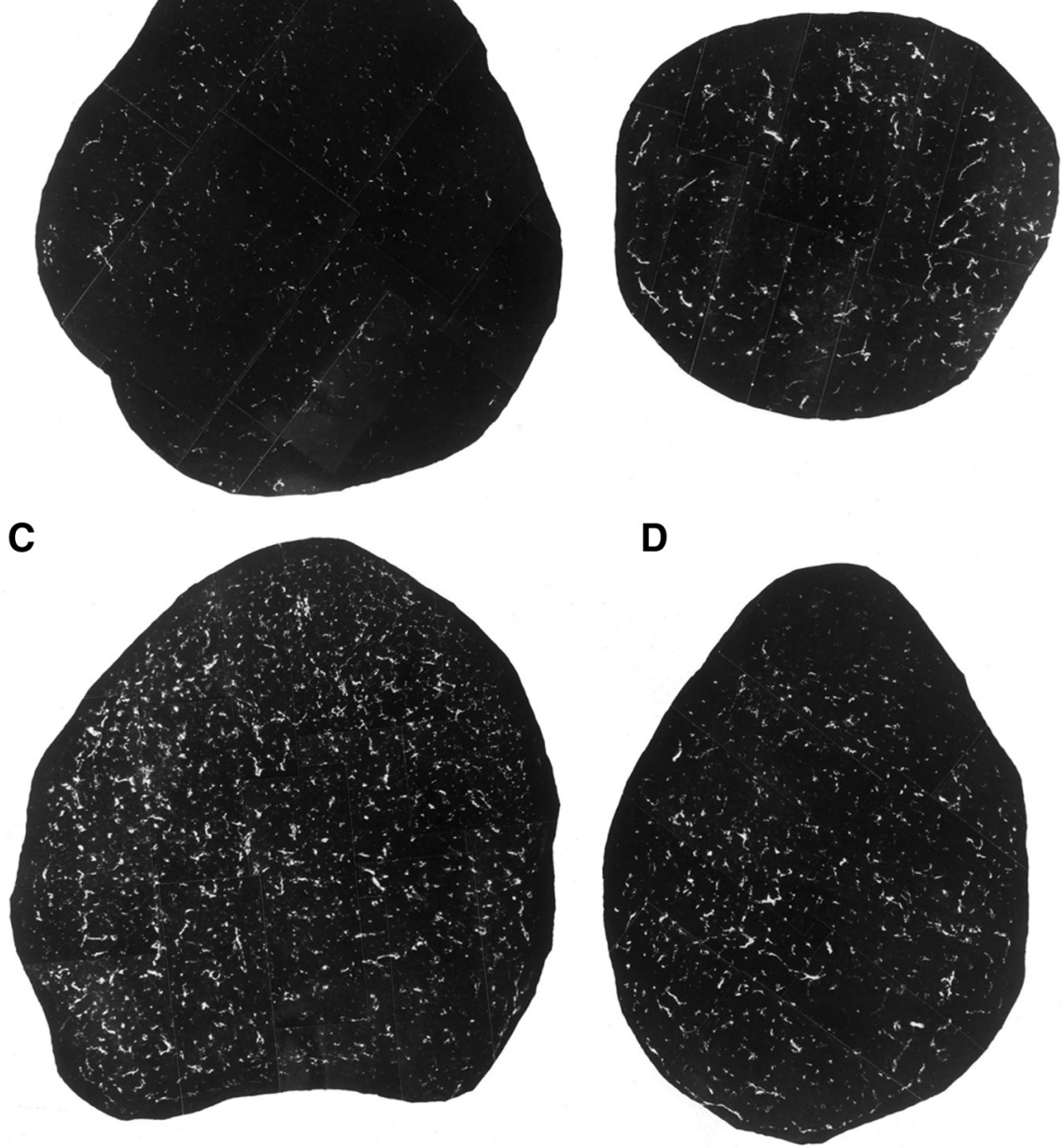

Figure 5. Micrographs showing catecholamine fluorescence in sections of pineal glands taken from previously lesioned $(\boldsymbol{A}, \boldsymbol{B})$ and sham-operated $(\boldsymbol{C}, \boldsymbol{D})$ animals. $\boldsymbol{A}, \boldsymbol{B}$, Sections were examined from pineal glands of two groups of animals 2 months after Table 2. The density of fluorescent processes in the particular sections shown in $\boldsymbol{A}$ and $\boldsymbol{B}$ are somewhat higher than the average densities presented in Table 2, whereas the densities in the sections shown in $\boldsymbol{C}$ and $\boldsymbol{D}$ are almost identical to the average densities for those groups. Top is anterior, and bottom is posterior. Magnification, $63 \times$.

Table 2. The density of fluorescent processes in the pineal gland 2 months after bilateral crushing of the CST

\begin{tabular}{lcc}
\hline & $\begin{array}{c}\text { Density of fluorescent } \\
\text { processes }\end{array}$ & $\begin{array}{l}\text { \% of respective sham-operated } \\
\text { control }\end{array}$ \\
\hline Sham & $23 \pm 3$ & $100 \%$ \\
CST crush & $7 \pm 2$ & $30 \%$ \\
Sham $+\alpha$-MNE & $20 \pm 3$ & $100 \%$ \\
CST crush $+\alpha$-MNE & $15 \pm 1$ & $75 \%$ \\
\hline
\end{tabular}

The density of fluorescent processes of sections of pineal glands was analyzed 2 months after bilateral crushing of the CST (CST Crush) or a sham operation (Sham). Two groups of animals were injected with $\alpha$-methylnorepinephrine ( $\alpha$-MNE) $1 \mathrm{~h}$ before removal of their pineal glands (CST Crush $+\alpha$-MNE; Sham $+\alpha$-MNE). The density of fluorescent processes ( \pm SEM) is the number of fluorescent processes counted divided by the number of grid point analyzed and multiplied by 100. Each group contains three to four pineal glands.

regenerated CSTs were at least as large as the responses of pineal glands from sham-operated animals. At the lowest frequency tested, $1 \mathrm{~Hz}$, NAT activity increased 8.2 -fold in the animals with regenerated CSTs, although no significant increase was seen in sham-operated animals $(p<0.05)$. 


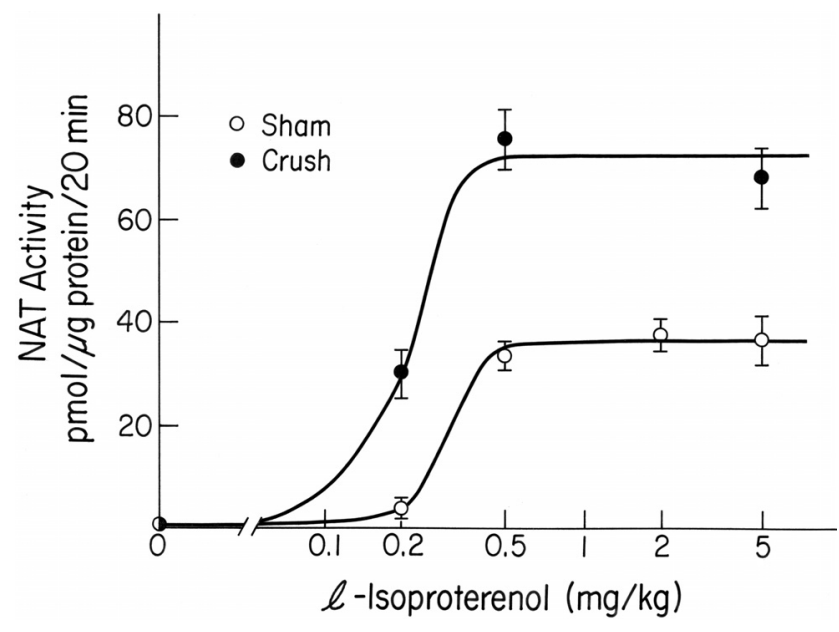

Figure 6. Sensitivity of pineal glands to isoproterenol 2 months after bilateral crushing of the CST. Two months after bilateral crushing of the CST (Crush) or a sham operation (Sham), isoproterenol was injected subcutaneously $5 \mathrm{~h}$ into the daytime, and pineal glands were removed for measurement of NAT activity $3 \mathrm{~h}$ later. Each point represents an average of three to five pineal glands, except for crush at $5.0 \mathrm{mg} / \mathrm{kg}$, which represents an average of two pineal glands. At all doses of isoproterenol, the pineal NAT response of rats with regenerated CST was significantly greater than that of sham-operated rats $(p<0.005$ at $0.2 \mathrm{mg} / \mathrm{kg} ; p<0.001$ at 0.5 $\mathrm{mg} / \mathrm{kg} ; p<0.025$ at $5.0 \mathrm{mg} / \mathrm{kg}$ ).

As pointed out above, although the nocturnal level of NAT activity in previously lesioned animals is low, a small, neurally dependent, nocturnal increase in enzyme activity is reestablished in these animals (Figs. 3, 4). To characterize the neural control of NAT activity in these animals further, we examined the pineal response to a brief light pulse in the middle of the dark period. Illnerová et al. (1979) first reported that such a light pulse leads to a rapid decrease in pineal NAT activity to daytime levels, and these levels are maintained for at least $5 \mathrm{~h}$ although the animals are maintained in the dark. Later, Drijfhout et al. (1996) found that such a 1 min light pulse dramatically decreases the release of norepinephrine and melatonin in the pineal gland. When we exposed previously sham-operated animals to $1 \mathrm{~min}$ of light in the middle of the dark period, followed by $1 \mathrm{~h}$ of darkness, NAT activity decreased by $98 \%$. Similarly, enzyme activity decreased by $85 \%$ in animals whose CSTs had been crushed 80 d earlier (Fig. 8).

\section{Discussion}

The pineal gland is innervated by axons whose cell bodies are located in the SCG. SCG neurons are generally electrophysiologically silent except when activated via the CST (Skok, 1973). The circuits controlling the pineal gland are driven by a circadian oscillator in the suprachiasmatic nucleus (SCN) (Borjigin et al., 2012), and this pathway controls the rhythm in pineal NAT. Thus, a bilateral lesion of the CST almost totally abolishes the nighttime rise in NAT activity (Klein et al., 1971; Fig. 2), whereas bilateral stimulation of these nerves during the daytime increases enzyme activity to peak nighttime values (Bowers and Zigmond, 1982; Fig. 7A).

In the present study, the CSTs were crushed, and time was allowed for the axons to reinnervate the SCG. Three months later, when extensive reinnervation has occurred, nocturnal NAT activity reached a plateau at $\sim 15 \%$ of control values. NAT activity in these animals did exhibit a day/night rhythm, although with a substantially diminished amplitude. Relesioning the CST de-

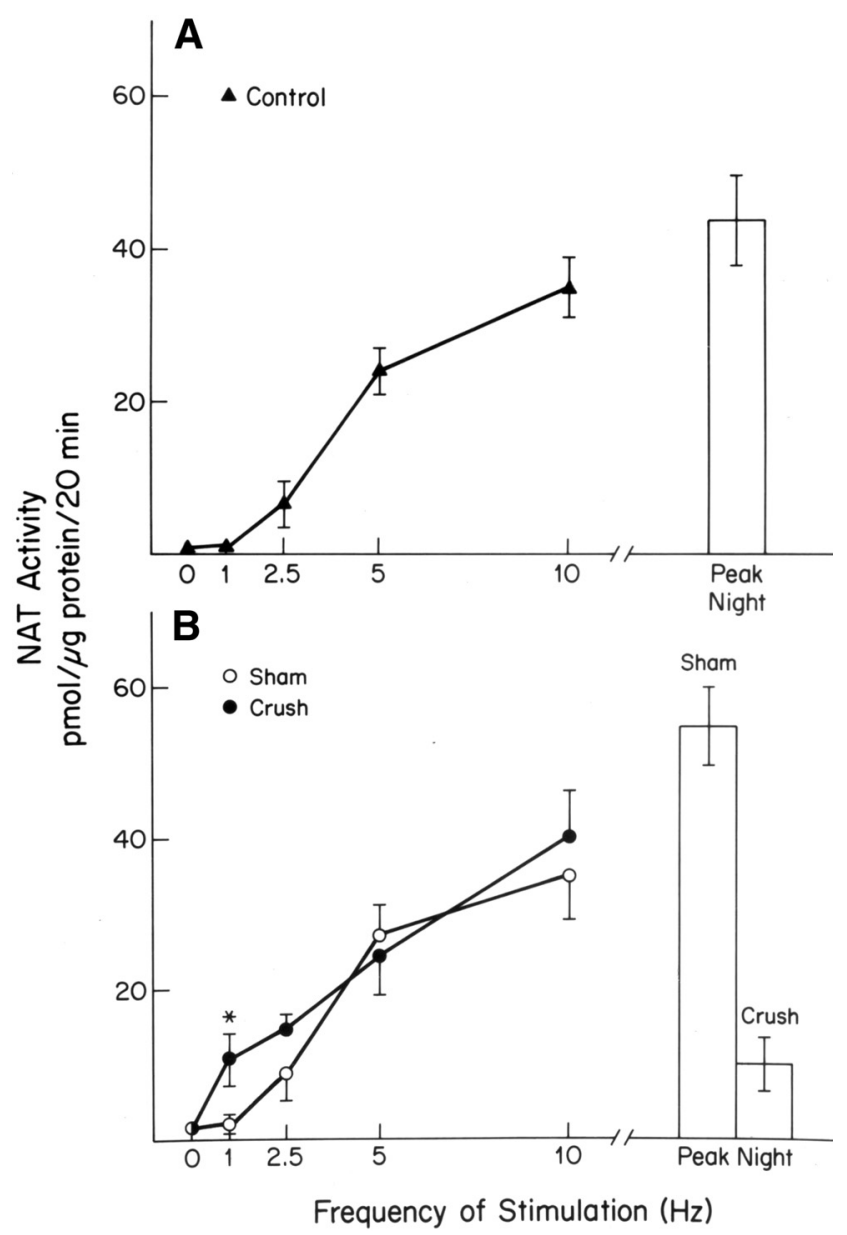

Figure 7. Frequency-response curve of the effect of bilateral stimulation of the CST on NAT activity in unoperated animals $(\boldsymbol{A})$ and in animals 3 months after bilateral crushing of the CST (filled circles) or sham operations (open circles) (B). Both CSTs were stimulated in anesthetized animals for $3 \mathrm{~h}$ during the daytime at frequencies of $1,2.5,5$, or $10 \mathrm{~Hz}$, immediately after which NAT activity was measured. In addition, $7-8 \mathrm{~h}$ into the dark period, pineal glands were removed from groups of unoperated animals (Peak Night; $A$ ), as well as groups of sham-operated and previously lesioned animals (Sham and (rush, Peak Night; $\boldsymbol{B}$ ) and assayed for enzyme activity. Each point or bar represents an average of six pineal glands. $\ln \boldsymbol{B},{ }^{*} p<0.05$, significant difference between sham and crush groups.

creased NAT activity, indicating that the partial recovery depended on regeneration of CST fibers.

Two types of explanations might account for the failure of more extensive recovery. The first is that, despite substantial regeneration, a quantitative deficit persists somewhere along the neural pathway regulating the pineal, resulting in reduced transmission of information to the gland. The second is that a qualitative defect exists so that, although conduction of action potentials and synaptic transmission are normal, inappropriate neural information reaches the pineal gland as a result of "mistakes" in the connections made by the regenerating axons.

With respect to the issue of quantitative deficits, regeneration of the CST is known to be extensive. By 3 months after the CSTs are crushed or frozen bilaterally, the following are known to be near normal: the number of fibers in the CST (Bray and Aguayo, 1974), the velocity of action potentials (Hopkins and Lambert, 1972), the number and distribution of synapses in the ganglia (Raisman et al., 1974; Ostberg et al., 1976), and the induction of ganglionic TH in response to reserpine (Raisman et al., 1974). 


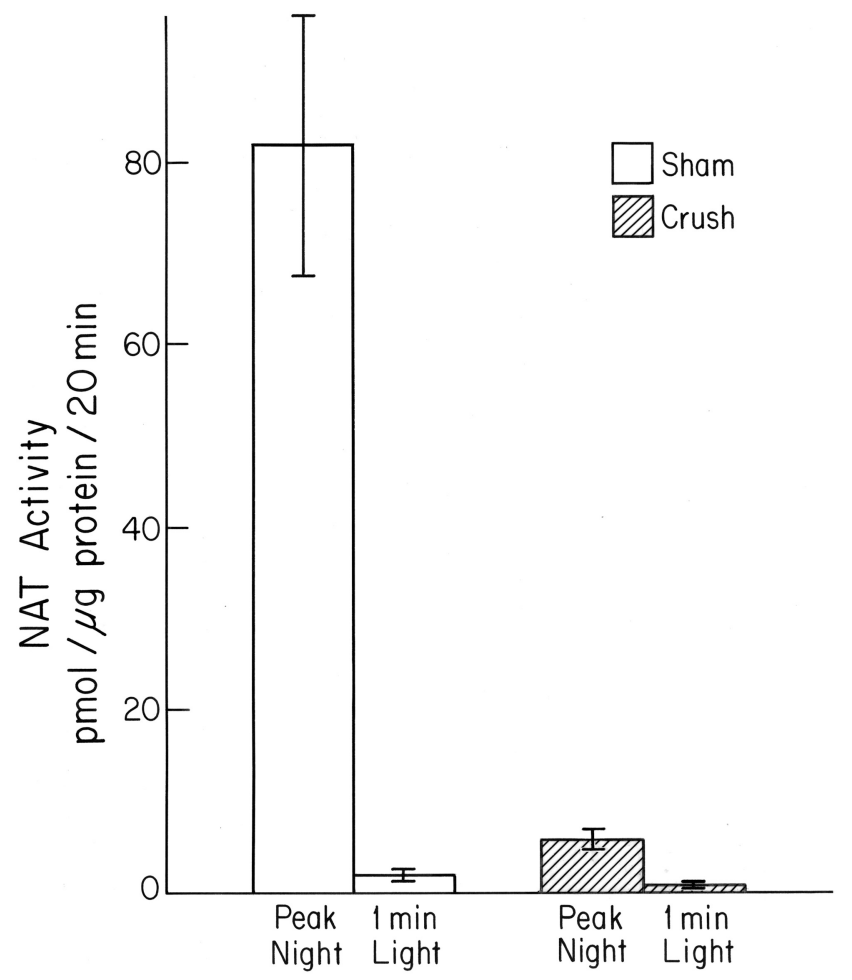

Figure 8. Effect of $1 \mathrm{~min}$ of light in the middle of the dark period on NAT activity. Seven to $8 \mathrm{~h}$ into the dark period, certain animals that had a sham operation or had their CSTs crushed bilaterally $80 \mathrm{~d}$ previously were exposed to $1 \mathrm{~min}$ of light and then returned to the dark for $1 \mathrm{~h}$. Compared with animals that were kept in darkness (Peak Night), animals that were exposed to light, in both the sham-operated group and the previously lesioned group, had reduced NAT activity ( $p<0.001$ in both cases). Each bar represents the data from five to eight pineal glands.

In the present study, we examined other quantitative properties and found no defects likely to cause the failure of recovery of pineal function. For example, our histochemical studies indicate that the density of the sympathetic innervation is not significantly changed. As to the sensitivity to $\beta$-adrenergic agonists, the glands from rats with regenerated CSTs were actually more responsive to isoproterenol at both low and high concentrations than are control glands. Such supersensitivity was shown by Deguchi and Axelrod (1973) to occur 2 weeks after both CSTs were lesioned. That supersensitivity is still present 2 months after a lesion, a time by which considerable regeneration has taken place, may reflect disuse supersensitivity resulting from a lower firing rate of many of the preganglionic nerves that reinnervate the "pineal" sympathetic neurons that in fact differ from those that originally innervated these neurons as discussed further below.

Nevertheless, some quantitative defects are known to be present in these animals after regeneration. For example, decreases have been found in the mean diameter of CST axons (Bray and Aguayo, 1974), in the average number of preganglionic fibers that innervate a single ganglion cell (Njå and Purves, 1977), and in the choline acetyltransferase activity of the ganglion (Raisman et al., 1974), and, of course, numerous other possibilities could be investigated. However, whether any of these defects produce a significant effect on end organ function is unclear. For example, a $50 \%$ decrease in the activity of choline acetyltransferase may, in fact, have no functional consequences for ganglionic transmission (Jope, 1979; Collier and Kwok, 1982).

Electrical stimulation of the CST (Fig. 7) was undertaken as a more global approach to asking whether reduced NAT activity resulted from quantitative or qualitative deficits. If quantitative deficits are responsible, regardless of what these deficits might be, then one might expect that stimulation of the regenerated CST, using a frequency of stimulation that increases NAT activity to peak nighttime values, would not be effective in raising NAT activity to these high values. Conversely, if the deficit is not a quantitative one, but rather the consequence of the type of neural information transmitted to the pineal gland during the light/dark cycle, then stimulation of the regenerated CST with an "appropriate" pattern of activity should increase NAT activity to its normal nighttime level. CST stimulation at $10 \mathrm{~Hz}$ and at a variety of lower frequencies was at least as effective in raising NAT activity in rats with regenerated CSTs as in sham-operated animals, thus strongly favoring the hypothesis that the neural information reaching the pineal has been altered. These results also suggest that activation of the pineal gland in the regenerated animals is not limited by the decrease seen in norepinephrine levels, possibly because these may primarily reflect transmitter in a reserve pool or because they are compensated by the known increased catecholamine biosynthetic capacity of the terminals (Rittenhouse and Zigmond, 1990).

There are at least two caveats to our interpretation of the stimulation experiment. First, the normal frequency and pattern of activity of the fibers that innervate the pineal gland are not known. However, the stimulation frequencies used here are in accord with values reported from electrophysiological studies on preganglionic sympathetic neurons (Polosa, 1968; Jänig and Schmidt, 1970; Passatore and Pettorossi, 1976). In addition, stimulation of the CST at $10 \mathrm{~Hz}$ in control animals produces an increase in NAT activity over time that closely resembles the nighttime rise in enzyme activity (Bowers and Zigmond, 1982). A second possible problem is the synchronous activation of all pineal preganglionic fibers, although the natural activity in these fibers may be asynchronous. However, it is noteworthy that studies in the rabbit SCG suggest that synchronous firing of functional groups of preganglionic fibers may occur (Skok and Ivanov, 1983).

Despite these caveats, our data raise the interesting possibility that selective patterns of synaptic connections have not been restored by those regenerating CST fibers that receive input from the SCN. On the surface, this possibility seems to contradict the studies referred to in the Introduction that demonstrated that aspects of specificity are restored by regenerating preganglionic nerve fibers. Langley $(1895,1897)$ found that stimulation of individual ventral roots in the cat resulted in activation of ganglion cells that innervated specific clusters of sympathetic end organs. Furthermore, he found that, after regeneration of the CST, this pattern of evoked end organ responses was restored with only minor changes. Njå and Purves (1977) expanded on these observations, including showing that, in control guinea pigs, as well as in guinea pigs with regenerated CSTs, each ganglion cell is innervated by a contiguous subset of ventral root fibers, with one root being dominant and adjacent roots having smaller effects. Nevertheless, each ventral root is known to contain a number of different functional subclasses of preganglionic fibers. For example, the first thoracic ventral root contains fibers that innervate ganglion cells that control pupillary dilation as well as the control of eyelid opening (Langley, 1895). Inappropriate matching of such functional subclasses would lead to transmission to a particular ganglion cell of neural information intended for a ganglion cell that innervates a different sympathetic end organ (Fig. 9). Whether or not such mismatching occurs during regeneration cannot be deduced from the experiments of Langley or Njå and Purves, because in these studies whole ventral roots, not individ- 

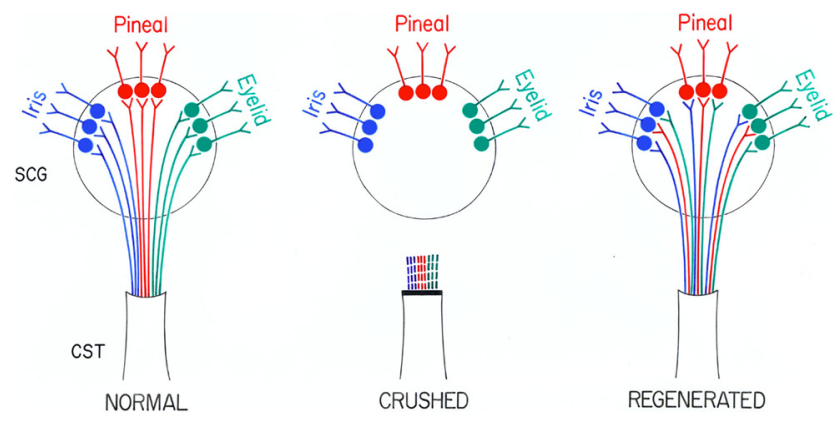

Figure 9. A diagram illustrating the present hypothesis concerning the synaptic connections made in the $S C G$ by regenerating preganglionic nerve fibers. It is hypothesized that postganglionic neurons innervating the iris, the pineal gland, and Mueller's muscle, which participates in the control of the opening of the eyelid (all of which reach these targets via the internal carotid nerves), are normally innervated by functionally distinct groups of preganglionic fibers. We propose that, after a lesion to the preganglionic CST, many functionally "inappropriate" connections are made between the regenerating preganglionic fibers and specific neurons in the SCG. However, note that not all of the connections are inappropriate, thus explaining the reestablishment of a circadian rhythm in NAT activity with a depressed amplitude.

ual functional subclasses of fibers, were stimulated. Thus, the functional pattern of reinnervation could be incorrect, even when other aspects of the ventral root pattern of ganglion cell innervation was restored to normal, and such a situation would be consistent with the failure of restoration of the normal rhythm in pineal NAT activity.

Another important question is whether the small rhythm that is reestablished after regeneration reflects the reformation of some functionally correct connections in the SCG. This interpretation is suggested by the experiment in which animals were exposed to a brief light pulse in the middle of the dark period. In control animals, this manipulation causes a decrease in NAT activity that is not reversed by returning the animals to the dark, probably because of a change at the level of the SCN (Trávnícková et al., 1996). We showed previously that this effect is not seen when the pineal gland is transplanted and reinnervated by collateral sprouts of neurons that innervate the iris and reasoned that this suppression is specific for pineal sympathetic neurons (Lingappa and Zigmond, 1987b). It is, therefore of considerable interest that, after regeneration of the CST, NAT activity is again under the control of the same or a functionally similar circadian oscillator. The reestablishment of this aspect of the neural control of the pineal gland supports the notion that the partially recovered pineal rhythm involves the reformation of some normal pineal circuits by the regenerating preganglionic nerve fibers.

Our previous work suggests an additional mechanism that might limit the synaptic effectiveness of whatever normal pineal circuits are reestablished. We showed that, in a situation in which both electrophysiologically active and inactive sympathetic neurons innervate the pineal gland, the latter can inhibit the synaptic efficacy of the former by a process of heteroneuronal uptake, namely the uptake of transmitter released by active nerve endings by neighboring inactive endings (Zigmond et al., 1981, 1985). Thus, by using a postsynaptic measure of functional recovery, we might be underestimating somewhat the extent of normal reinnervation.

It is believed that pineal melatonin feeds back and alters the firing of neurons in the SCN that are involved in controlling the sympathetic input to the pineal gland (Dubocovich et al., 2003; Scott et al., 2010; Pfeffer et al., 2012). Thus, alteration in the synthesis and release of melatonin immediately after preganglionic nerve crush and/or at some later time could affect the output of the hypothalamic circadian clock. Nevertheless, the rhythm in NAT activity in the previously lesioned animals was similar to that seen in sham-operated animals (Fig. 4), suggesting that the circadian clock had not been fundamentally altered.

In summary, our data are consistent with the hypothesis that, when the regenerating axons of the lesioned CSTs form synapses in the SCG, mistakes are made but some correct connections are formed, resulting in a limited recovery of normal pineal function.

\section{References}

Borjigin J, Zhang LS, Calinescu AA (2012) Circadian regulation of pineal gland rhythmicity. Mol Cell Endocrinol 349:13-19. CrossRef Medline

Bowers CW, Zigmond RE (1980) Electrical stimulation of the cervical sympathetic trunks mimics the effects of darkness on the activity of serotonin: $\mathrm{N}$-acetyltransferase in the rat pineal. Brain Res 185:435-440. CrossRef Medline

Bowers CW, Zigmond RE (1982) The influence of the frequency and pattern of sympathetic nerve activity on serotonin $N$-acetyltransferase in the rat pineal gland. J Physiol 330:279-296. Medline

Bowers CW, Baldwin C, Zigmond RE (1984a) Sympathetic reinnervation of the pineal gland after postganglionic nerve lesion does not restore normal pineal function. J Neurosci 4:2010-2015. Medline

Bowers CW, Dahm LM, Zigmond RE (1984b) The number and distribution of sympathetic neurons that innervate the rat pineal gland. Neuroscience 13:87-96. CrossRef Medline

Bray GM, Aguayo AJ (1974) Regeneration of peripheral unmyelinated nerves. Fate of the axonal sprouts which develop after injury. J Anat 117:517-529. Medline

Brownstein M, Holz R, Axelrod J (1973) The regulation of pineal serotonin by a beta adrenergic receptor. J Pharmacol Exp Ther 186:109-113. Medline

Collier B, Kwok YN (1982) Superior cervical ganglion: chemical considerations. In: Progress in cholinergic biology: model cholinergic synapses (Hanin I, Goldberg AM, eds), pp 169-190. New York: Raven.

De la Torre JC (1980) An improved approach to histofluorescence using the SPG method for tissue monoamines. J Neurosci Methods 3:1-5. CrossRef Medline

De la Torre JC, Surgeon JW (1976) A methodological approach to rapid and sensitive monoamine histofluorescence using a modified glyoxylic acid technique: the SPG method. Histochemistry 49:81-93. CrossRef Medline

Deguchi T, Axelrod J (1972) Sensitive assay for serotonin $N$-acetyltransferase activity in the rat pineal. Analyt Biochem 50:174-179. CrossRef Medline

Deguchi T, Axelrod J (1973) Supersensitivity and subsensitivity of $\beta$-adrenergic receptor in pineal gland regulated by catecholamine transmitter. Proc Natl Acad Sci U S A 70:2411-2414. CrossRef Medline

Drijfhout WJ, van der Linde AG, de Vries JB, Grol CJ, Westerink BH (1996) Microdialysis reveals dynamics of coupling between noradrenaline release and melatonin secretion in conscious rats. Neurosci Lett 202:185188. CrossRef Medline

Dubocovich ML, Rivera-Bermudez MA, Gerdin MJ, Masana MI (2003) Molecular pharmacology, regulation and function of mammalian melatonin receptors. Front Biosci 8:d1093-d1108. CrossRef Medline

Erny RE, Berezo MW, Perlman RL (1981) Activation of tyrosine 3-monooxygenase in pheochromocytoma cells by adenosine. J Biol Chem 256:13351339. Medline

Gabella G (1976) Structure of the autonomic nervous system, pp 3-43. London: Chapman and Hall.

Hopkins AP, Lambert EH (1972) Conduction in regenerating unmyelinated fibres. Brain 95:213-222. CrossRef Medline

Illnerová H, Vanĕcek J, Krecek J, Wetterberg L, Sääf J (1979) Effect of one minute exposure to light at night on rat pineal serotonin $\mathrm{N}$-acetyltransferase and melatonin. J Neurochem 32:673-675. CrossRef Medline

Ip NY, Zigmond RE (1985) Long-term regulation of tyrosine hydroxylase activity in the superior cervical ganglion in organ culture: effects of nerve stimulation and dexamethasone. Brain Res 338:61-70. CrossRef Medline

Iversen LL (1975) Uptake processes for biogenic amines. In: Handbook of psychopharmacology, Vol 3, Biochemistry of biogenic amines (Iversen LL, Iversen SD, Snyder SH, eds), pp 381-442. New York: Plenum.

Jänig W, Schmidt RF (1970) Single unit responses in the cervical sympathetic trunk upon somatic nerve stimulation. Pflugers Arch 314:199-216. CrossRef Medline 
Jope RS (1979) High affinity choline transport and acetyl CoA production in brain and their roles in the regulation of acetylcholine synthesis. Brain Res Rev 1:313-344. CrossRef Medline

Klein DC, Weller JL (1970) Indole metabolism in the pineal gland: a circadian rhythm in $\mathrm{N}$-acetyltransferase. Science 169:1093-1095. CrossRef Medline

Klein DC, Weller JL, Moore RY (1971) Melatonin metabolism: neural regulation of pineal serotonin: acetyl coenzyme A $N$-acetyltransferase activity. Proc Natl Acad Sci U S A 68:3107-3110. CrossRef Medline

Langley JN (1895) Note on regeneration of prae-ganglionic fibres of the sympathetic. J Physiol 18:280-284.

Langley JN (1897) On the regeneration of pre-ganglionic and postganglionic visceral nerve fibres. J Physiol (Lond) 22:215-230.

Larsen PJ, Enquist LW, Card JP (1998) Characterization of the multisynaptic neuronal control of the rat pineal gland using viral transneuronal tracing. Eur J Neurosci 10:128-145. CrossRef Medline

Lingappa JR, Zigmond RE (1987a) A histochemical study of the adrenergic innervation of the pineal gland: evidence for overlap of the innervation from the two SCG and for sprouting following unilateral denervation. Neuroscience 21:893-902. CrossRef Medline

Lingappa JR, Zigmond RE (1987b) Pineal transplants in oculo: limitations on the ability of collateral sprouts of foreign neurons to establish normal function. J Neurosci 7:3525-3528. Medline

Lowry OH, Rosenbrough NJ, Farr AL, Randall RJ (1951) Protein measurement with the Folin phenol reagent. J Biol Chem 193:265-275. Medline

Njå A, Purves D (1977) Re-innervation of guinea-pig superior cervical ganglion cells by preganglionic fibres arising from different levels of the spinal cord. J Physiol 272:633-651. Medline

Njå A, Purves D (1978) Specificity of initial synaptic contacts made on guinea-pig superior cervical ganglion cells during regeneration of the cervical sympathetic trunk. J Physiol 281:45-62. Medline

Ostberg AJ, Raisman G, Field PM, Iversen LL, Zigmond RE (1976) A quantitative comparison of the formation of synapses in the rat superior cervical ganglion by its own and by foreign nerve fibres. Brain Res 107:445-470. CrossRef Medline

Parfitt A, Weller JL, Sakai KK, Marks BH (1975) Blockade by ouabain or elevated potassium ion concentration of the adrenergic and adenosine cyclic $3^{\prime}, 5^{\prime}$-monophosphate-induced stimulation of pineal serotonin $N$-acetyltransferase. Mol Pharmacol 11:241-255. Medline
Passatore M, Pettorossi VE (1976) Efferent fibers in the cervical sympathetic nerve influenced by light. Exp Neurol 52:66-82. CrossRef Medline

Pfeffer M, Rauch A, Korf HW, von Gall C (2012) The endogenous melatonin (MT) signal facilitates reentrainment of the circadian system to lightinduced phase advances by acting upon MT2 receptors. Chronobiol Int 29:415-429. CrossRef Medline

Polosa C (1968) Spontaneous activity of sympathetic preganglionic neurons. Can J Physiol Pharm 46:887-896. CrossRef Medline

Raisman G, Field PM, Ostberg AJ, Iversen LL, Zigmond RE (1974) A quantitative ultrastructural and biochemical analysis of the process of reinnervation of the superior cervical ganglion in the adult rat. Brain Res 71:1-16. CrossRef Medline

Rando TA, Bowers CW, Zigmond RE (1981) Localization of neurons in the rat spinal cord which project to the superior cervical ganglion. J Comp Neurol 196:73-83. CrossRef Medline

Rittenhouse AR, Zigmond RE (1990) Nerve stimulation in vivo acutely increases tyrosine hydroxylase activity in the superior cervical ganglion and its end organs. Brain Res 524:156-159. CrossRef Medline

Scott FF, Belle MD, Delagrange P, Piggins HD (2010) Electrophysiological effects of melatonin on mouse Per1 and non-Per1 suprachiasmatic nuclei neurones in vitro. J Neuroendocrinol 22:1148-1156. CrossRef Medline

Skok VI (1973) Physiology of autonomic ganglia. Tokyo: Igaku Shoin.

Skok VI, Ivanov AY (1983) What is the ongoing activity of sympathetic neurons? J Auton Nerv Syst 7:263-270. CrossRef Medline

Trávnícková Z, Sumová A, Peters R, Schwartz WJ, Illnerová H (1996) Photoperiod-dependent correlation between light-induced SCN c-fos expression and resetting of circadian phase. Am J Physiol 271:R825-R831. Medline

Volkman PH, Heller A (1971) Pineal N-acetyltransferase activity: effect of sympathetic stimulation. Science 173:839-840. CrossRef Medline

Zigmond RE, Baldwin C, Bowers CW (1981) Rapid recovery of function after partial denervation of the rat pineal gland suggests a novel mechanism for neural plasticity. Proc Natl Acad Sci U S A 78:3959-3963. CrossRef Medline

Zigmond RE, Baldwin C, Bowers CW (1985) Rapid recovery of pineal function after partial denervation: a possible role for heteroneuronal uptake of transmitter in modulating synaptic efficacy. J Neurosci 5:142-150. Medline 